\title{
META-ORgANIZING FIRMS' CAPABILITIES FOR SUSTAINABLE INNOVATION: A CONCEPTUAL FRAMEWORK
}

\author{
Héloïse Berkowitz \\ CNRS, UMR5303, TSM-Research, France \\ Institut Barcelona d'Estudis Internacionals, Spain \\ Forthcoming in Journal of Cleaner Production
}

\begin{abstract}
:
Organizing practices at the collective level of firms and entrepreneurs, i.e. 'meta-organizing', is a necessity for the development and diffusion of sustainable innovations. This paper seeks to build a meta-organization approach of sustainable innovation's governance. To do so, we conducted a three-stage literature review and analysis to 1) identify organizational capabilities that businesses need to acquire to develop sustainable innovations, 2) uncover attributes of meta-organizations as devices for governance, 3 ) relate these attributes to the capabilities for sustainable innovations. Our contributions are twofold: first we build a more comprehensive understanding of organizational capabilities, insisting on the overlooked importance of accountability, in addition to existing literature on anticipation, resilience, reflexivity, responsiveness and inclusion. Second, we highlight the key role of meta-organizations in facilitating the meta-governance of these capabilities. We propose a research agenda to further investigate these issues in several families of meta-organizations.
\end{abstract}

KEYWORDS: sustainable innovation, sustainable development, capabilities, meta-organization, meta-organizing, meta-governance 


\section{INTRODUCTION}

Innovation is widely considered to hold the keys for sustainable development (SD) of our societies (Boons, Montalvo, Quist, \& Wagner, 2013; Matos \& Silvestre, 2013). A technological break in, or a deployment of, carbon capture technologies would for instance greatly help mitigate climate change (Chaudhry et al., 2013; Wennersten, Sun, \& Li, 2015). However, not all kinds of innovations are desirable, since emerging technologies can have disastrous impacts on environment or health - take hydraulic fracturing for instance (Bagatin, Klemeš, Reverberi, \& Huisingh, 2014). An increasing body of literature seeks to take into account negative externalities of innovation, and studies what defines responsible or sustainable innovation (Koops, Oosterlaken, Romijn, Swierstra, \& van den Hoven, 2015; Owen, Bessant, \& Heintz, 2013). To date, however, little work has thoroughly examined how firms and entrepreneurs may collectively develop and build capabilities to encourage these sustainable innovations.

Sustainable innovation is commonly defined as one that leads to "socially desirable outcomes" (Stahl, Eden, \& Jirotka, 2013; Voegtlin \& Scherer, 2015; Von Schomberg, 2011). Such sustainable innovation implies "a collective commitment of care for the future through responsible stewardship of science and innovation in the present" (Owen, Stilgoe, et al., 2013, p. 36). To foster the development of sustainable innovation, regulation may at first be considered the best alternative but has proved so far unable to positively impact practices (De Saille, 2015; Lee \& Petts, 2013). On the contrary, literature has shown that a governance turn is necessary, thus shifting the weight from top-down, hard law, regulatory frameworks, to soft-law, and bottom-up or horizontal distribution of governance of sustainable innovation (Davis \& Horst, 2015; Fung \& Wright, 2003; Lee \& Petts, 2013).

In that perspective, a growing body of literature studies meta-organizations, organizations which members are themselves organizations (Ahrne \& Brunsson, 2008). Such unconventional organizations (Brès, Raufflet, \& Boghossian, 2017) play a key role in the sectoral governance of sustainable business practices, i.e. those that create shared value for populations and the 
environment (Berkowitz, Bucheli, \& Dumez, 2017). Such studies have focused on corporate social responsibility (Berkowitz et al., 2017), climate change mitigation (Chaudhury et al., 2016) or general management practices (Leys \& Joffre, 2014). However, little work has analyzed their role in the governance of sustainable innovation, an issue which remains underdeveloped, as Koops (2015) notes. Thus, scholarship mainly addresses motivational or definitional approaches of sustainable innovation, making the governance dimension marginal. Without an adequate analysis of collective organizing for sustainable innovation's diffusion, we undervalue the role firms and entrepreneurs can play in collectively building their capabilities. Ultimately, this leads to underestimating their broader role in the sustainable development (SD) of our societies.

In this paper, we follow Zollo, Cenamo and Neumann's (2013) call to study the how of sustainability (means to foster the development of sustainable innovations), rather than the why (motivational reasons to pursue sustainable innovations) or the what (definitions of sustainable innovations). To do so, we carried out a three-stage literature review analysis, that followed general guidelines for developing literature reviews and research agendas (Adapa, Bhullar, \& de Souza, 2016; Christ \& Burritt, 2015; Jiao \& Boons, 2014). We first identified organizational capabilities needed for sustainable innovations. We then uncovered the attributes of metaorganizations that play a key role in sustainable sectoral governance. Finally, we showed how these attributes may help develop capabilities for sustainable innovation.

Our paper shows that the development and diffusion of sustainable innovations requires six key organizational capabilities: anticipation of future changes and negative externalities of innovation, resilience to changes, reflexivity about environment, society and change, responsiveness, i.e. the capacity to adapt to changing circumstances, inclusion of stakeholders and accountability towards them. Meta-governance of such capabilities, i.e. framing, encouraging and controlling its development in organizations, requires devices that facilitate collective action and learning among organizations. Meta-organizations present various attributes that allow to collectively build and diffuse these capabilities as we show in this paper. These attributes include facilitating coopetition - i.e. combined advantages of cooperation and competition -, informal collective learning, knowledge transfers and information production. Another important attribute 
of meta-organizations as a governance device is that they function on consensus and 'heterarchy' (horizontal organizing of work). Finally, they act as a platform that can gather multiple stakeholders, with reporting and accountability mechanisms. Our findings show how these attributes encourage the development of organizational capabilities for sustainable innovation.

Our paper contributes to the literature on sustainable innovation first by providing a more comprehensive approach of organizational capabilities for sustainable innovation. Indeed, we insist on the relatively neglected importance of accountability in existing frameworks. Second, the paper contributes to the debate on governance, by showing how meta-organizations may play a role in the collective building of such capabilities in firms and entrepreneurs. This "metagovernance" approach, i.e. the collective organization and development of organizational capabilities through meta-organizations, offers a fruitful way to theorize the necessary governance turn in innovation studies. This leads us to identify challenges for future research based on families of meta-organizations, from global value chain governance devices to entrepreneurial meta-organizations. This research agenda aims to further investigate how business collective action and multi-stakeholder initiatives may contribute to meta-organize capabilities for sustainable innovation.

The paper is organized as follows. We first examine the literature on sustainable innovation and the governance turn. We then describe the methodology used to develop our literature review. Next, we uncover organizational capabilities for sustainable innovation, as well as meta-organizational attributes and discuss how they relate to the capabilities, before illustrating our framework with cases. Ultimately, we discuss our contributions to the governance of sustainable innovation and propose a research agenda.

\section{THE DEVELOPMENT OF SUSTAINABLE INNOVATIONS}

We first synthesize elements of a definition of 'sustainable innovation' before reviewing what literature has named a governance turn. 


\section{What is a sustainable innovation?}

As we argued in introduction, an innovation per se is not necessarily sustainable or responsible. On the contrary, Stilgoe, Owen and Macnaghten (2013) show that negative externalities of innovations are often unanticipated, and therefore disastrous. This raises the question of sustainable innovation's definition. Carrillo-Hermosilla et al. (2010) describe it as an "innovation that improves sustainability performance". But then what is sustainability performance? In a report, von Schomberg (2011) characterizes 'sustainable' as "contributing to the EU's objective of sustainable development. The EU follows the 1997 UN "definition" of sustainable development, consisting of economic, social and environmental dimension in their mutual dependency" (Von Schomberg, 2011, p. 9). This can be achieved by following an overarching anchor objective of being "socially desirable", i.e. capturing "the relevant, and more specific normative anchor points of the Treaty on the European Union, such as "Quality of life", “Equality among men and women” etc.” (Von Schomberg, 2011, p. 9).

Further, the author defines sustainable innovation (and research) as "a transparent, interactive process by which societal actors and innovators become mutually responsive to each other with a view on the (ethical) acceptability, sustainability and societal desirability of the innovation process and its marketable products (in order to allow a proper embedding of scientific and technological advances in our society)" (Von Schomberg, 2011, p. 9). This echoes to another attempt at defining sustainable innovations as "(1) innovations [that] avoid harming people and the planet, (2) innovations [that] 'do good' by offering new products, services, or technologies that foster SD, and (3) global governance schemes [that] are in place that facilitate innovations that avoid harm and 'do good"” (Voegtlin \& Scherer, 2015, p. 1).

Sustainable innovation and growing literature on related topics (social innovation, responsible innovation, green innovation) therefore provides "a new approach towards innovation, in which social and ethical aspects are explicitly taken into account (...) and economic, socio-cultural, and environmental aspects are balanced" (Blok \& Lemmens, 2015, p. 20). There seems to exist a common agreement that sustainable innovation is one aligned with 
social needs, and sustainability impacts (De Saille, 2015) and that sustainable research and innovation processes should lead to "socially desirable outcomes" (Stahl et al., 2013).

\section{How to foster the development of sustainable innovation?}

Zollo, Cennamo and Neumann's (2013) call to study the 'how' of sustainability (how to foster the development of sustainable innovations?), rather than the 'why' (why pursue sustainable innovations?) or the 'what' (what are sustainable innovations?). So how to foster the development and diffusion of sustainable innovations?

Reactive approaches of governance frameworks based on regulation have shown little success (Lee \& Petts, 2013). De Saille (2015) studies how the general European framework for responsible research and innovation may actually remain a vague concept with no transformative power on norms, discourses, institutions etc. Self-governance may offer an alternative solution to avoid this decoupling between discourse and practices. Koops (2015) indeed argues that "existing governance structures and regulatory frameworks can sometimes be poorly equipped to accommodate certain innovations or system transitions $[\ldots]$ this underlines the importance of integrating the governance perspective within the whole cycle of responsible innovation processes, so that technologies, practices, and governance can fruitfully co-evolve" (2015, p. 10). In line with this work, recent literature has begun to explore how tackling grand challenges requires specific governance devices (Etzion, Gehman, Ferraro, \& Avidan, 2015).

Davis and Horst (2015) further call for more research on governance at the level of actors of responsible innovation. The authors argue that a governance turn is required. A governance turn aims to shift the weight from top-down, hard law, regulatory framework, to soft-law or selfregulatory, more bottom-up or horizontal distribution of governance. This resonates with the development of participatory governance in the context of innovation, that entails more stakeholder involvement (Fung \& Wright, 2003). In that paper, Fung and Wright (2003) address the role of governments and international organizations but less the one of firms and entrepreneurs, through what is increasingly studied as sectoral governance or business collective action based on meta-organizations (Berkowitz \& Bor, 2017). Similarly, Hillman, Nilsson, 
Rickne and Magnusson (2011) show that to develop and diffuse innovations benefitting society as a whole, thinking in terms of governance is needed. The authors address different questions, from governance levels to processes. However, they do not look at the meta-organizational level, which can be cross-sectoral, trans-national or even multi-stakeholder, and plays a key role in sustainability governance and transformation (Berkowitz \& Bor, 2017).

Meta-organizations are unconventional organizations (Brès et al., 2017), where members are themselves organizations (Ahrne \& Brunsson, 2008; Gulati, Puranam, \& Tushman, 2012). Meta-organizations can be solely of made of businesses, or be mixed, as in multi-stakeholder groups that also gather civil society organizations. Such meta-organizations play a key role in collectively building capabilities, especially in diffusing socially responsible practices (Berkowitz et al., 2017) or more generally management capabilities (Leys \& Joffre, 2014). Little work has examined how these meta-organizations, as a governance device, may help build and diffuse capabilities for sustainable innovations. It is the purpose of this article.

\section{Analytical And Methodological Approach}

This paper aims to study the role of meta-organizations in the governance of sustainable innovation. Ultimately, we seek to develop a research agenda on meta-organizing capabilities for sustainable innovation, i.e. collectively organizing and shaping practices at the level of firms and entrepreneurs.

To do so, we developed a research methodology and heuristic that would achieve three goals: 1) identify organizational capabilities of sustainable innovation for firms and entrepreneurs, 2) uncover specific attributes of meta-organizations that make them a useful device for sectoral governance, and 3) demonstrate how these attributes relate to and foster the development of identified organizational capabilities. This literature review originally brings together literatures on organizational capabilities and sectoral governance based on meta-organizations, to address the issue of sustainable innovation's meta-governance. By meta-governance, we mean the governance of organizational capabilities at the level of organizations, through metaorganizations. 
The methodology and analysis followed general qualitative data analysis guidelines (Adapa et al., 2016; Christ \& Burritt, 2015; Jiao \& Boons, 2014). The objective of this study was to methodologically and rigorously synthesize, review and integrate "representative literature on a topic $[\ldots]$ such that new frameworks and perspectives on the topic are generated" (Torraco, 2005, p. 356; Christ \& Burritt, 2015). This systematic literature review allows building and presenting a research agenda on meta-organizations and sustainable innovations.

For the literature review, we included the following databases: Science Direct, EBSCO, Emerald Management Plus, JSTOR, ProQuest, Springer Link, Taylor and Francis and Wiley Interscience. In the first step of the review, we conducted the review based on a structured keyword search of these databases, using the following terms: "responsible innovation", "sustainable innovation", "governance of innovation". One major research paper resulted from this search: “Developing a framework for responsible innovation", by Stilgoe, Owen and Macnaghten (2013). We based our analysis on this paper that presents key parameters for responsible innovation, i.e. anticipation, resilience, reflexivity, responsiveness and inclusion. These parameters also emerged from other papers. But we also identified another organizational capability that was not present in this framework: accountability. At this stage, we had identified six main organizational capabilities that emerged from the analysis of the resulting literature, synthesized in Table 1.

Table 1: Identifying organizational capabilities for sustainable innovation

\begin{tabular}{ll}
\hline Organizational capability & Main references from the literature \\
\hline Anticipation & (Corral, 2003; Jänicke, 2008; Stilgoe et al., 2013) \\
\hline Resilience & (Beermann, 2011; Stilgoe et al., 2013) \\
\hline Reflexivity & (Stephens \& Graham, 2010; Stilgoe et al., 2013; Sykes \& \\
& Macnaghten, 2013) \\
\hline Responsiveness & (Gaziulusoy, Boyle, \& McDowall, 2013; Stilgoe et al., 2013) \\
\hline Inclusion & (Boström, 2006; Boström, Jönsson, Lockie, Mol, \& \\
& Oosterveer, 2015; Francesch-Huidobro, 2015; Fung \& Wright, \\
& 2003; Matos \& Silvestre, 2013; Nielsen, Reisch, \& Thøgersen, \\
& 2016; van Kleef \& Roome, 2007) \\
\hline Accountability & (Grutter \& Egler, 2004; Hankins, 2013; Iles, 2007) \\
\hline
\end{tabular}

We then used each capability identified, i.e. "anticipation, resilience, reflexivity, responsiveness, inclusion, accountability" as keywords in relation with the keyword "innovation" 
to verify that we had not missed any important criterion through cross-references, and in a snowball effect (Miles \& Huberman, 1994).

In the second part of the review, we sought to analyze the features of meta-organizations that fostered one or the other of these capabilities. We conducted a literature review, looking for emergent attributes of meta-organizations that may have an impact on governance mechanisms. Table 4 synthesizes the attributes of meta-organizations that play a key role in sectoral governance. We develop their analysis in the next section.

Table 2: Attributes of meta-organizations as a device for sectoral governance

\begin{tabular}{ll}
\hline Attributes of meta-organizations & Main references from the literature \\
\hline Act as a platform & (Ciborra, 1996; Gawer, 2014) \\
\hline $\begin{array}{l}\text { Consists of an association of other } \\
\text { organizations }\end{array}$ & (Berkowitz \& Bor, 2017; Ahrne \& Brunsson, \\
\hline Functions by heterarchy rather than hierarchy & (Ahrne \& Brunsson, 2008; Stark, 2009) \\
\hline Makes decisions on consensus & (Ahrne \& Brunsson, 2008; Bor, 2014) \\
\hline Has a low-cost structure & (Berkowitz \& Bor, 2017; Berkowitz \& \\
& Dumez, 2016) \\
\hline $\begin{array}{l}\text { Includes heterogeneous actors from direct } \\
\text { competitors to stakeholders }\end{array}$ & (Berkowitz et al., 2017; Boström, 2006; \\
\hline $\begin{array}{l}\text { Permits coopetition, dialogue and } \\
\text { information capture }\end{array}$ & Clarysse, Wright, Bruneel, \& Mahajan, 2014) \\
\hline $\begin{array}{l}\text { Facilitates knowledge transfers and collective } \\
\text { learning }\end{array}$ & (Berkowitz et al., 2017) \\
\hline $\begin{array}{l}\text { Produces information for members and } \\
\text { outreaching }\end{array}$ & al., 2014; Gulati et al., 2012) \\
\hline $\begin{array}{l}\text { Results in self-regulation and industry } \\
\text { shaping }\end{array}$ & (Berkowitz \& Bor, 2017; Malcourant, Vas, \& \\
\hline $\begin{array}{l}\text { Produces reporting mechanisms and } \\
\text { enhances social responsibility }\end{array}$ & (Lawton, Rajwani, \& Minto, 2017; Rajwani, \\
\hline
\end{tabular}

Our third and last step consisted in analyzing how the meta-governance (i.e. governance through meta-organization) attributes relate to the sustainable innovation capabilities, i.e. in which sense meta-organizations may contribute to building or improving members' capabilities. To do so, we conducted several case studies aimed at illustrating the role of meta-organizations in this capability-building. We chose cases that varied in terms of members (sectors, types of 
firms), but also in terms of governance form (trade association, incubator, industrial cluster), to

cover diverse empirical phenomena. Table 3 presents a synthesis of the cases used.

Table 3: Synthesis of cases of sustainable innovation's meta-governance

\begin{tabular}{|c|c|c|}
\hline $\begin{array}{l}\text { Organizational } \\
\text { capabilities }\end{array}$ & Meta-organizational case & Description \\
\hline Anticipation & $\begin{array}{l}\text { Marine Sound \& Life Joint } \\
\text { Industry Program (JIP } \\
\text { IOGP) }\end{array}$ & $\begin{array}{l}\text { Anticipating regulatory risks in the oil } \\
\& \text { gas industry regarding underwater } \\
\text { noise pollution, assessing } \\
\text { environmental impacts of } \\
\text { technological innovations to mitigate } \\
\text { the effects of noise pollution }\end{array}$ \\
\hline Resilience & $\begin{array}{l}\text { Global Industry } \\
\text { Group } \\
\text { IPIECA/IOGP) }\end{array}$ & $\begin{array}{l}\text { Pooling knowledge and experience on } \\
\text { the Deepwater Horizon explosion to } \\
\text { build innovative techniques for the } \\
\text { whole oil and gas industry }\end{array}$ \\
\hline Reflexivity & $\begin{array}{lr}\text { Global Industry } & \text { Response } \\
\text { Group } & \text { (GIRG, } \\
\text { IPIECA/IOGP) } & \\
\end{array}$ & $\begin{array}{l}\text { Examining the limitations of the } \\
\text { innovative technique of ISB (in-situ } \\
\text { burning technique) }\end{array}$ \\
\hline Inclusion & $\begin{array}{lr}\text { Flemish } & \text { Science } \quad \& \\
\text { Technology } & \text { Innovation } \\
\text { system } & \end{array}$ & $\begin{array}{l}\text { Including of a wide range of actors } \\
\text { (public administration and research } \\
\text { centers, start-ups, incumbents, venture } \\
\text { capital, etc.) }\end{array}$ \\
\hline Responsiveness & StartX & $\begin{array}{l}\text { By being flexible and offering tools to } \\
\text { facilitate change, an incubation center } \\
\text { acts as a partial organizational that } \\
\text { enhances responsiveness for member- } \\
\text { organizations }\end{array}$ \\
\hline Accountability & Fair Labor Association & $\begin{array}{l}\text { Producing norms to ensure a } \\
\text { sustainable workplace on the whole } \\
\text { supply chain, with accountability } \\
\text { mechanisms for member-organizations }\end{array}$ \\
\hline
\end{tabular}

We now turn to the analysis of our framework on meta-organizing sustainable innovation.

\section{META-ORGANIZING SUSTAINABLE INNOVATION: A CONCEPTUAL FRAMEWORK}

In this section, we first present the six key organizational capabilities that firms and entrepreneurs need to collectively build to develop sustainable innovation. We then uncover metaorganizations features that give them advantages as governance devices. Finally, we show in which sense they relate to and may encourage the former organizational capabilities, thus developing a conceptual framework to "meta-organize" sustainable innovation. 


\section{Organizational capabilities for sustainable innovations}

To foster SD, sustainable innovation needs to be based on a set of key organizational capabilities that we identified through a literature review: anticipation, resilience, reflexivity, responsiveness, inclusion and accountability (see Table 1).

First, Stilgoe, Owen and Macnaghten (2013) argue that anticipation is a key parameter to understand what they call responsible innovation, and that we call here sustainable. Anticipation consists in a systematic questioning of emerging technologies' potential impacts on environment and society, to increase resilience and shape the evolution and regimes of innovation. In addition, anticipation of regulatory changes is needed in the context of highly complex and insecure systems (Corral, 2003; Jänicke, 2008). Related to anticipation, resilience capability appears crucial to ensure that sustainable innovation can resist on the long run, especially to deal with system risks (Beermann, 2011). Being able to anticipate and to develop resilience thinking involves a strong capacity of reflexivity on the part of actors, institutions, stakeholders. This capacity of reflexivity about, e.g. impacts on environment and society, may enable all actors in a field to become aware of their own limitations, especially of knowledge (Stilgoe et al., 2013). In the same line of thought, Sykes and Macnaghten highlight the importance of reflexivity and dialogue in opening up public debates on innovation (Sykes \& Macnaghten, 2013).

Another key criteria for sustainable innovation is responsiveness, that is to say the capacity to adapt to unforeseen exogenous shocks, to stakeholders and public demands, and to changing circumstances (Stilgoe et al., 2013). Inclusion, the fifth parameter for a sustainable innovation framework, describes the necessary engagement of not only core stakeholders (Freeman, Wicks, \& Parmar, 2004) but also members of the wider public (civil society at large) in hybrid forums (Callon, Lascoumes, \& Barthe, 2009). Finally, sustainable innovation requires openness, or transparency, which translates into a strong need for accountability to ensure sustainable industrial production (Grutter \& Egler, 2004; Iles, 2007). Accountability requires organizations to communicate on their practices to their different stakeholders (whether it be the 
public or regulatory authorities for instance). Hankins (2013) also raises the question of accountability and openness in building capabilities for sustainable innovation.

These capabilities, needed for sustainable innovations, can be more easily and less costly developed collectively at the meta-organizational level, as we show next.

\section{Meta-organizations as a governance device}

Meta-organizations, organizations which members are themselves organizations, appear as a key device to govern organizations and organize business collective actions (Ahrne \& Brunsson, 2008; Gulati et al., 2012; Spillman, 2017). They have been thoroughly studied in their multiple empirical forms, and above all as trade associations (March, 2007; March \& Simon, 1958), although they have only recently been coined as meta-organizations.

Meta-organizations cover a broad range of collective action forms, including trade associations and multi-stakeholder groups (Berkowitz et al., 2017), platform organizations (Ciborra, 1996), co-working spaces or fab labs that encourage the development of innovative entrepreneurial companies (Fabbri \& Charue-Duboc, 2013), technological clusters (Clarysse et al., 2014). As a different form of meta-organization, regional clusters describe the geographical availability, concentration and resulting synergies of different actors such as universities and research organizations, entrepreneurial firms, established companies and venture capital firms (Fleming, King, \& Juda, 2007; Saxenian, 1996, 2006)

Ciborra (1996) describes platforms as meta-organizations: "A platform is a metaorganization, a formative context that molds structures, and routines, shaping them into wellknown forms, such as the hierarchy, the matrix and even the network, but on a highly volatile basis" (Ciborra, 1996, p. 103). More specifically, a platform is a meta-organization in the sense that it constitutes a system of assets available on a collaborative structure that allows different member-organizations to efficiently derive value from it (Gawer, 2014; Gawer \& Cusumano, 2014; Meyer \& Lehnerd, 2002). Fab Labs are platforms or meta-organizations which make possible technical prototyping to encourage innovation and invention's development. Incubators 
of start-ups, such as StartX, Stanford non-profit business incubator, constitute another example of meta-organizations specifically dedicated to developing innovative companies.

Meta-organizations are also what Ahrne and Brunsson (2010) call partial organizations. The authors define five criteria that circumscribe a complete organization: membership, hierarchy, rules, monitoring and sanction. Complete organizations meet all five criteria. Firms, for instance, select their employees through individuals' recruitment process. In these organizations, hierarchy forms are then instituted among members. Some of them gain decisionmaking power (Child, 2005) and the authority to oblige other members, while others are expected to obey (Weber, 1921). This hierarchy is a traditional defining feature of organizations and is embodied in contractual employer-employee relationships (Weber, 1921; Coase, 1937). Power to command, or hierarchy, leads eventually to the definition of rules that members are required to abide by (March, Schulz, \& Zhou, 2000; Weber, 1921). And the existence of rules implies the need for monitoring members' compliance (Weber, 1921) and for both positive and negative sanctions (Ahrne \& Brunsson, 2010). Only meeting all five criteria designs a "complete" organization (Ahrne \& Brunsson, 2010; Ahrne, Brunsson, \& Seidl, 2016; Rasche et al., 2013).

Meta-organizations consists of an association of other organizations (i.e. membership of organizations) but they however present little to almost no hierarchy (Ahrne \& Brunsson, 2008). They therefore function on consensus (Bor, 2014; Malcourant et al., 2015). They are often based on what Stark called "heterarchy", that is to say a more cooperative decision making process and organizing, by opposition with vertically-organized, hierarchical organizations (Stark, 2009). Meta-organizations often lack the resources to carefully monitor members or the power to sanction them, apart from exclusion (Ahrne \& Brunsson, 2008). For all these reasons, metaorganizations constitute partial organizations, which make them flexible and less costly to implement than complete organizations (Berkowitz \& Bor, 2017).

As a forum bringing together different member-organizations, including competitors, meta-organizations facilitate "coopetition", i.e. the combined advantages of cooperation and competition (Berkowitz \& Bor, 2017; Brandenburger \& Nalebuff, 1996). They and facilitate knowledge transfers and capacity building (Berkowitz \& Bor, 2017; Spillman, 2017). Their main 
activity therefore consists in information for members and outreaching either internal members or external members through lobbying activities (Berkowitz \& Bor, 2017; Spillman, 2017). As such, they contribute to self-regulating and shaping industries (Lawton et al., 2017; Rajwani et al., 2015). Studies on meta-organizations and capacity building have often focused on corporate social responsibility (Berkowitz et al., 2017), climate change mitigation (Chaudhury et al., 2016) or diffusion of management practices in general (Leys \& Joffre, 2014). Little work has thoroughly examined their role in sustainable innovation governance. Yet they play an important role for innovation.

\section{Meta-organization and organizational capabilities for sustainable innovation}

So far, we have identified six capabilities needed for sustainable innovations and we have uncovered the attributes of meta-organizations as a device for sectoral governance. We now turn to analyze how these attributes relate to sustainable innovation's organizational capabilities, thus making meta-organizations a useful device for the governance of sustainable innovation. We use the cases defined in the methodology section, and synthesized in Table 3. Table 4 presents a synthesized view of how each meta-organization attribute may foster organizational capabilities.

Table 4: Relating sustainable innovation to meta-organization's attributes

\begin{tabular}{|c|c|}
\hline Sustainable innovation capabilities & Meta-organization attributes \\
\hline $\begin{array}{l}\text { Anticipation of risks (Stilgoe et al., 2013) } \\
\text { such as regulatory changes (Corral, 2003; } \\
\text { Jänicke, 2008) }\end{array}$ & $\begin{array}{l}\text { Through coopetition, capturing weak signals } \\
\text { across sectors and from regulators (Berkowitz, } \\
\text { Bucheli \& Dumez 2016), platform dimensions } \\
\text { (Ciborra, 1996; Gawer, 2014) }\end{array}$ \\
\hline $\begin{array}{l}\text { Resilience (Beermann, 2011; Stilgoe et } \\
\text { al., 2013) }\end{array}$ & $\begin{array}{l}\text { Collective learning, knowledge transfers, } \\
\text { information pooling on rare events (Ahrne \& } \\
\text { Brunsson, 2005, 2008; Clarysse et al., 2014; } \\
\text { Gulati et al., 2012; Malcourant et al., 2015) }\end{array}$ \\
\hline $\begin{array}{l}\text { Reflexivity (Stephens \& Graham, 2010; } \\
\text { Stilgoe et al., 2013; Sykes \& } \\
\text { Macnaghten, 2013) }\end{array}$ & $\begin{array}{l}\text { Workshops, information production, outreaching } \\
\text { activities (Berkowitz \& Bor, 2017; Malcourant et } \\
\text { al., 2015) }\end{array}$ \\
\hline $\begin{array}{l}\text { Responsiveness (Gaziulusoy et al., 2013; } \\
\text { Stilgoe et al., 2013) }\end{array}$ & $\begin{array}{l}\text { Flexibility from acting like a partial organization } \\
\text { (Ahrne \& Brunsson, 2010) }\end{array}$ \\
\hline $\begin{array}{l}\text { Inclusion (Boström, 2006; Boström et al., } \\
\text { 2015; Francesch-Huidobro, 2015) of } \\
\text { end-users (Nielsen et al., 2016) and } \\
\text { stakeholders (Fung \& Wright, 2003; }\end{array}$ & $\begin{array}{l}\text { Inclusiveness (Boström, 2006; Brès et al., 2017), } \\
\text { multi-stakeholder groups, consensus-based (Bor, } \\
\text { 2014), heterarchical (Stark, 2009) partial } \\
\text { organizing (Ahrne \& Brunsson, 2008; }\end{array}$ \\
\hline
\end{tabular}




\begin{tabular}{ll}
\hline $\begin{array}{l}\text { Matos \& Silvestre, 2013; van Kleef \& } \\
\text { Roome, 2007) }\end{array}$ & $\begin{array}{l}\text { Malcourant et al., 2015) geographical inclusion } \\
\text { (Clarysse et al., 2014; Porter, 1990) }\end{array}$ \\
\hline Accountability (Grutter \& Egler, 2004; & $\begin{array}{l}\text { Self-regulation (Lawton et al., 2017; Rajwani et } \\
\text { al., 2015; Spillman, 2017), reporting mechanisms }\end{array}$ \\
& $\begin{array}{l}\text { and corporate social responsibility enabler } \\
\text { (Berkowitz et al., 2017; Chaudhury et al., 2016; } \\
\text { Rasche et al., 2013) }\end{array}$ \\
\hline
\end{tabular}

Anticipation. As we have shown, Stilgoe, Owen and Macnaghten (2013) define anticipation as one of the key parameters for responsible innovation. Anticipation consists in a systematic questioning of the impacts of emerging technologies to shape the evolution and regimes of innovation. This includes being able to anticipate future regulatory changes in order to better adapt to them (Corral, 2003; Jänicke, 2008). By facilitating coopetition, i.e. the combined advantages of cooperation and competition (Brandenburger \& Nalebuff, 1996), metaorganizations allow to capture weak informational signals about threats and opportunities (Berkowitz et al., 2017). Capturing weak informational signals facilitate the assessment of emerging innovations as well as anticipating regulatory risks related to these innovations.

Take for instance underwater noise pollution. The International Oil and Gas Producers association (IOGP) launched in 2005 the Marine Sound and Life joint industry initiative to conduct research on the issue of underwater noise pollution, regulatory risks, impact of noise on animals and innovations to mitigate them. The effects of underwater noise of anthropic activities are far-reaching and affect all marine life, from cetaceans to invertebrates and fish. Exposure of marine fauna to sound pollution may well result in a range of behavioral responses, physiological effects and physical injuries in marine mammals and other species (note that there is an impact not only on mammals but also fish and invertebrates), as well as ecological, population and cumulative effects, with dire consequences on the overall worldwide ecosystem (Marine Mammal Commission, 2007).

The industrywide initiative has enabled members to anticipate the institutional regulatory frameworks that have started to emerge in Europe and the US. These require of industries and countries to address this issue and reduce activities' noise footprint: from oil and gas to marine renewables. The 2008 Marine Directive for instance provides a legal framework for seas 
protection. Its overarching goal consists in achieving "good environmental status" of EU's Marine Waters by 2020 . Good environmental status describes "the environmental status of marine waters where these provide ecologically diverse and dynamic oceans and seas which are clean, healthy and productive" (Marine Strategy Framework Directive, 2008 Art. 3(5)).

The 2008 Marine Strategy Framework Directive (MSFD) has developed 11 qualitative descriptors for this Good Environmental Status. From maintaining biological diversity, to protecting ecosystems against non-indigenous species, reducing fish over-exploitation, and minimizing eutrophication, the Directive forces countries and marine industries to assess their environmental impacts and especially negative externalities of their innovation. The $11^{\text {th }}$ descriptor concerns introduction of energy, including underwater noise. This has four main implications: the first one is protecting marine ecosystems, i.e. developing clean, healthy, productive seas that are fully functioning and resilient to human-induced environmental impacts. The second implication is preventing the decline of biodiversity and guaranteeing that human related substances and energy introduction in the ocean do not cause pollutions. Then, it implies ensuring sustainable uses of EU marine resources and thus their continuity for future generations and lastly, building common approaches and fostering cooperation and sustainable innovation at the EU and regional level.

The Marine Sound and Life joint industry initiative precisely anticipated this kind of regulation and aimed to provide research and knowledge in order to address the $11^{\text {th }}$ descriptor.

"The purpose of this study is to investigate current and future potential treatment options for all sources of underwater sound, including sources associated with exploration, construction, transport, drilling, and production. "'(Spence et al., 2007, p. 1)

Cooperation among competitors, i.e. coopetition, through meta-organizations allows pooling costs of systematic questioning of the impacts of emerging technologies to increase resilience and shape the evolution and regimes of innovation.

Resilience. To build innovation that is resilient to unexpected social, societal or environmental changes, such as catastrophes and regulatory risks, leveraging on collective 
experience is a necessity. Meta-organizations permit this collective experience that single organization would lack otherwise. It is the case of environmental groups of companies such as IPIECA in the oil and gas industry, a meta-organization that specializes on environmental and social issues. This meta-organization facilitates the collective design and development of responses to sustainability issues (Berkowitz et al., 2017). Pooling knowledge on rare events to develop sustainable innovations is one of the advantages of these meta-organizations. In 2010, the Deepwater Horizon platform, that BP rented, exploded in the Gulf of Mexico, resulting in an unprecedented ecological disaster. The international oil and gas producers' association, IOGP, and IPIECA launched the Global Industry Response Group (GIRG) to learn from this catastrophe and share resulting knowledge with the whole sector:

"This Group was tasked with identifying ways to prevent the recurrence of such an incident and to identify learning opportunities both with respect to the cause of, and response to, the incident. Part of this effort involved the formation of a subgroup on Oil Spill Response (OSR). This group was comprised of nominees from IOGP member companies, from the IPIECA Oil Spill Working Group (OSWG), from Oil Spill Response Limited (OSRL), and from other industry organizations, associations and spill response cooperatives, as appropriate.” (IPIECA-IOGP Oil Spill Response Joint Industry Project, 2014)

IPIECA and IOGP (2014) produced this report which presents an innovative response technique to oil spills: the in-situ burning (ISB). According to this report, ISB can be used to combust vapors from slicks on a water or land surface. ISB response technique converts the hydrocarbon mixture into predominantly carbon dioxide and water with some particulates, or soot, which is then released into the atmosphere. The report assesses ISB's applicability in several different environments (land, ice or other hard surfaces, or water surface). It has already been used in a small number of cases, on relatively small inland and inshore spills in North America since the late 1950s.

The conclusion of the collective efforts behind this report is that ISB operations require different parameters to be efficient: first, sufficient fuel to ignite the concentration of vapors, an 
ignition source to trigger the burn, but also sufficient quantities of fuel to sustain a burn on the surface. Oil and gas companies would have had a hard time reach these concrete conclusions on their own, especially with the rare occurrence of such events as the Macondo incident. It is therefore necessary to pool knowledge and efforts in meta-organization to enhance the sector's resilience.

"Several types of fire booms tested in the above-mentioned large-scale evaluations are not readily available today; it may therefore be useful to reflect on the experiences gained from the response to the Deepwater Horizon incident at the Macondo Prospect in 2010. A number of ISB operations were carried out during this incident and a variety of different types of fire booms were utilized. The observations concluded that, in general, actively water-cooled booms were able to withstand more burns than those of an intrinsically fire-resistant design." (IPIECA-IOGP Oil Spill Response Joint Industry Project, 2014, p. 10)

Meta-organizations' characteristics can help build resilience, especially on rare events. However, as we have shown in our literature review, reflexivity and responsiveness are also needed to build sustainable innovations.

Reflexivity and responsiveness. Reflexivity on the part of actors, institutions, stakeholders, means to ensure that everyone in the field is aware of their own limitations, especially of knowledge (Stilgoe et al., 2013; van Kleef \& Roome, 2007). Meta-organizations facilitate such reflexivity thanks to their main activity which is information production. They can do so through workshops or outreaching activities (Berkowitz \& Bor, 2017; Malcourant et al., 2015). They also include various sectors in these organizational practices, in supra-sectoral or cross-sectoral meta-organizations for instance, which allows information pooling (Berkowitz et al., 2017),

"Although a great deal of information has been available on the efficiencies of equipment used for in-situ burning in marshland and inland environments, it was not until the Macondo incident that the importance of in-situ burning on water was realized. The ISB 
operations undertaken during the Macondo incident provided useful information on the relative performance of different types of fire resistant booms available at the time of the incident. However, it should be noted that some manufacturers have since modified the materials and design of their products. It is important to recognize that every incident will be different, and that the same items of specialized ISB equipment may demonstrate different levels of performance according to the circumstances in which they are deployed. Appropriate response techniques should always be determined with consideration given to local and national regulations, as well as to the specific incident characteristics.” (IPIECA-IOGP Oil Spill Response Joint Industry Project, 2014, p. 16) By their very nature, meta-organizations favor reflexivity, because they bring together heterogeneous actors with different expertise and knowledge. They encourage collective discussions on problems and externalities through knowledge pooling and transfers, for instance on rare events or emerging problems as we showed earlier. This is meta-organizations enable members to develop reflexivity as an organizational capability.

Next, relating to reflexivity, we have shown that responsiveness is the capacity to adapt to unforeseen exogenous shocks, to stakeholders and public demands, and to changing circumstances (Stilgoe et al., 2013). We have highlighted that meta-organizations present features of what Ahrne and Brunsson (2010) called partial organization. Flexibility from acting like a partial organization is what facilitates responsiveness of member-organizations.

One of the roles of incubation centers for start-ups is to develop start-ups' responsiveness capability. StartX, a Stanford non-profit business incubator, constitutes another example of metaorganizations specifically dedicated to developing innovative companies. Indeed, StartX brings together startups at different stage of development:

"The Accelerator Program for First-time Founders (relative to your stage) will focus on building your network of mentors and peers who can help you learn how to succeed. For example, if you are raising a Series B for the first time, apply to the firsttime founders program to learn from mentors and other entrepreneurs who have successfully raised Series B rounds. 
The Accelerator Program for Experienced Entrepreneurs (Serial entrepreneurs and growth-stage companies) is designed for founders that have had past success in previous companies of the same stage, and assumes you can hit the ground running. This track will focus on surrounding each serial entrepreneur with tactical help and other serial entrepreneurs like you to help build your company bigger, better, and more efficiently than the last." (StartX Website)

"StartX typically admits first-time founders, late-stage companies, serial entrepreneurs, and industry or domain experts. We support all industries, historically ranging from biotech, informatics, medical device, hardware, fintech, cleantech, and non-profit to the more traditional consumer/enterprise/health IT \& deep tech. The program is designed for companies of all stages, whether you have only recently developed an initial prototype or have already raised Series B+." (StartX Website)

StartX also gives access to resources, from office space to legal advice. Without StartX, many new startups and young entrepreneurs would not benefit from such resources. By being flexible and offering tools to facilitate change, this incubation center acts as a partial organizational that enhances responsiveness for member-organizations.

Inclusion. Nielsen, Reisch and Thøgersen (2016) highlight the importance of focusing on end-users in the development of sustainable innovation. But not just end-users need to be included in this development. Sustainable innovation requires the active and wider involvement of stakeholders who have a better understanding of local contexts and constraints:

"joint action toward sustainability should also be organized by and with the consent or participation of many different stakeholders, especially people who are locally involved, through inclusive networks spanning organizational levels” (van Kleef \& Roome, 2007, p. 44)

Meta-organizations that are geographically anchored, such as regional clusters (Porter, 1990) can facilitate this inclusion of stakeholders. Clusters or districts are defined as geographically bounded productive systems, where several actors (firms, universities, public 
agencies) are involved and collaborate at very different stages and through very different ways. Their objectives are also varied, although it is often the production of a homogeneous product or service (Pyke \& Sengenberger, 1990) "A district comprises a cluster of firms producing something which is homogeneous in one way or another, positioning themselves differently on the market. Thus, the district could be defined as being a cluster, plus a peculiar relationship amongst firms." (Brusco, 1990, p. 14)

These clusters include companies, suppliers, service providers, and associated institutions in a given field, such as research centers. Also called regional innovation systems (Braczyk, Cooke, \& Heidenreich, 1998), or technology hotspots (Clarysse et al., 2014), they encourage the development of innovation. Clarysse, Wright, Bruneel and Mahajan (2014) study a cluster in Flandres, Belgium, the Flemish Science \& Technology Innovation system. In this case, the cluster gathers more than a hundred of innovative start-ups but also public administrations and agencies, knowledge institutes, universities and university colleges, scientific institutes, public research organizations, university hospitals, various collective research centers, incubation centers, private companies, venture capital firms, etc. Innovation and value creation result here from bridging the gap between knowledge and business ecosystems, the authors show. However, to be sustainable, these innovations also require the other dimensions we have highlighted.

Meta-organizations present characteristics that permit to develop, at least separately, member-organizations' capabilities of anticipation, resilience, reflexivity, responsiveness and inclusion. But all these also call for accountability to build sustainable innovation.

Accountability. Meta-organizations can ensure accountability of member-organizations because they facilitate the development of self-regulation and reporting mechanisms to stakeholders (Rasche et al., 2013). Meta-organizations, as partial organizations, develop soft law or self-regulation (Lawton et al., 2017; Rajwani et al., 2015; Spillman, 2017). They also collectively develop reporting mechanisms and corporate social responsibility best practices (Berkowitz et al., 2017; Chaudhury et al., 2016). 
Fair Labour Association (FLA) is a meta-organization which gathers companies, civil society representatives, universities and research centers. Companies that become members of the FLA commit to respect ten Principles of Fair Labor and Responsible Sourcing (and/or Production). They also agree to uphold Workplace Code of Conduct developed by FLA in their whole supply chain (not just in the companies themselves). The Code of Conduct seeks to protect the workers in manufacturing industries (clothing, footwear, electronics, agricultural products, etc.) FLA develops a model of collaboration, accountability, and transparency for companies. Sustainable innovation also means being accountable to stakeholders, whether internal or external (Patrus, Neto, Coelho, \& Teodosio, 2013). It means that workplace is also an important dimension of sustainable innovation, and as such decent and humane working conditions are necessary (see Figure 1). FLA Code's standards are based on International Labor Organization standards and internationally accepted good labor practices, which they control in their members:

"FLA holds affiliated companies accountable for enforcing its Workplace Code of Conduct in the factories, farms and facilities they use. To verify this, FLA has instituted a rigorous system for assessing working conditions, remedying violations and verifying progress. Working with FLA staff, Independent External Assessors randomly visit approximately five percent of facilities supplying affiliated companies each year. Since 2002, FLA has conducted more than 1,500 assessments - the results of which are posted below. View results by company, location, or year and learn more about how these assessments uncover issues and lead to improvements for workers." http://www.fairlabor.org/transparency/workplace-monitoring-reports 
Figure 1: Fair Labour Association: summary of code violations of Under Armour, Inc., Year 2015, Factory Reference F00000003423, Country China

\begin{tabular}{|c|c|c|}
\hline FLA Code Element & $\begin{array}{l}\text { Number of } \\
\text { Violations }\end{array}$ & Violations \\
\hline \multirow[t]{4}{*}{ Compensation } & 4 & General Compliance Compensation \\
\hline & & Deposit of Legally Mandated Deductions \\
\hline & & Workers Awareness and Understanding of Compensation \\
\hline & & Compensation Disputes \\
\hline \multirow[t]{11}{*}{ Employment Relationship } & 11 & General/Human Resource Management Systems \\
\hline & & Terms and Conditions/New Employee Orientation \\
\hline & & Terms and Conditions/Communication \\
\hline & & Terms and Conditions/Supervisor Training \\
\hline & & $\begin{array}{l}\text { Administration of Fringe Benefits/Holidays, Leave, Legal Social Benefits and } \\
\text { Bonuses }\end{array}$ \\
\hline & & Industrial Relations \\
\hline & & Industrial Relations/Right to Organize, Bargain and Participate in Legal Strikes \\
\hline & & Work Rules and Discipline \\
\hline & & Skills Development/Management of Performance Reviews \\
\hline & & Health, Safety, and Environmental Management System/Policies and Procedures \\
\hline & & Termination and Retrenchment/General Policies and Procedures \\
\hline $\begin{array}{l}\text { Freedom of Association and Collective } \\
\text { Bargaining }\end{array}$ & 1 & General Compliance Freedom of Association \\
\hline Harassment and Abuse & 1 & General Compliance Harassment or Abuse \\
\hline \multirow[t]{3}{*}{ Hours of Work } & 3 & General Compliance Hours of Work \\
\hline & & Rest Day \\
\hline & & Maintenance of Reasonable Levels of Staff \\
\hline \multirow[t]{4}{*}{ Health, Safety and Environment } & 5 & General Compliance Health, Safety, and Environment \\
\hline & & Ergonomics \\
\hline & & $\begin{array}{l}\text { Document Maintenance/Workers Accessibility and Awareness } \\
\text { Evacuation Requirements and Procedure }\end{array}$ \\
\hline & & Chemical Management and Training \\
\hline
\end{tabular}

Because they include various stakeholders, and because they produce norms, selfregulation and reporting mechanisms, certain forms of meta-organizations such as the Fair Labor Association may develop members' organizational capability for accountability.

\section{DISCUSSION AND RESEARCH AGENDA}

The aim of this paper was to provide a governance framework to organize the development of sustainable innovation at the meta-organizational level or collective level of organizations. We sought to better understand how to "meta-organize" firms' and entrepreneurs' capabilities for sustainable innovation.

We first identified six main organizational capabilities for sustainable innovation: anticipation of negative externalities of innovation and future changes, resilience to changes, reflexivity about society and change, responsiveness, i.e. the capacity to adapt to changing circumstances, inclusion of stakeholders, and accountability towards them. Collective action among organizations can help develop and diffuse these capabilities better than individual organizations do on their own by pooling costs, risks and knowledge, especially on rare events or emerging issues. Therefore, meta-organizations, as a governance device, appear as crucial to 
collectively build and develop sustainable innovation capabilities among member-organizations. Thanks to their characteristics, e.g. heterarchical platform gathering organizational members, facilitating coopetition, weak signal capture and knowledge transfers, in a flexible organizational form, they constitute a neutral space of dialogue, negotiation and capacity building that facilitates sustainable innovation's development and diffusion.

This paper first contributes to the literature on sustainable innovation by synthesizing organizational capabilities. Our main theoretical contribution consists in completing Stilgoe, Owen and Macnaghten (2013) framework, i.e. anticipation, resilience, reflexivity, responsiveness and inclusion, with an additional central dimension: accountability. We shed light on this capability's importance, in line with various studies in the literature (Boström et al., 2015; Francesch-Huidobro, 2015; Grutter \& Egler, 2004; Iles, 2007; Matos \& Silvestre, 2013). This also resonates with ongoing work on participatory governance (Fung \& Wright, 2003) but furthers the need for accountability capacity building in members (Hankins, 2013).

We also contribute to the literature by uncovering the role meta-organizations could play in the governance of sustainable innovation. Literature has shown that a governance turn is necessary, thus shifting the weight from top-down regulatory frameworks, to soft bottom-up distribution of sustainable innovation's governance, and has called for further investigations (Davis \& Horst, 2015; Fung \& Wright, 2003; Lee \& Petts, 2013). Little work has examined the role of meta-organizations in such governance of sustainable innovation (Berkowitz \& Bor, 2017). We show how meta-organizations' attributes enable them, as a meta-governance device, to collectively build and develop members' organizational capabilities for sustainable innovation. As unconventional organizations (Brès et al., 2017), meta-organizations allow systems and industries to transition towards more sustainability, through what Etzion, Gehman, Ferraro and Avidan (2015) have called robust action. Our paper suggests a "meta-governance" approach, i.e. collective organization and development of organizational capabilities through metaorganizations, thus offering a fruitful way to theorize the governance turn in innovation studies. Our findings further provide the bases for a research agenda on meta-governance innovation for SD. 


\section{Implications for future research}

Future research could fruitfully use this capability-attribute framework to systemically analyze and compare meta-organizations' actions in the diffusion of sustainable innovation. Indeed, our findings invite to study a broad typology of meta-organizations, or families of metaorganizations. Their varying role in the development of sustainable innovations can be investigated through our framework by focusing on their different empirical forms: fablabs, CSR meta-organizations, global value chains, eco-patent pools and crowdfunding platforms.

Fablabs, co-working spaces, incubators of start-ups and other entrepreneurial metaorganizations. We showed in this paper that a family of meta-organizations specifically focuses on entrepreneurial development (Fabbri \& Charue-Duboc, 2013). We call these entrepreneurial meta-organizations. Our framework invites to study more extensively the characteristics of this type of meta-organization and how it facilitates anticipation, resilience, reflexivity, responsiveness, inclusion and accountability for entrepreneurs. Future research could also investigate the broader implications of meta-organizations as a governance device for entrepreneurs' knowledge acquisition and diffusion (Capdevila, 2015; Cohendet, Grandadam, Simon, \& Capdevila, 2014). This question is all the more relevant for fab cities (such as the fab city initiative in Barcelona, which regroups fab labs at the city level) and transnational or international groupings of fab labs (such as Betahaus) (Bohas et al., 2016; Capdevila \& Zarlenga, 2015).

CSR business oriented meta-organizations and multi-stakeholder governance forms. Literature has shown the diversity of meta-organizations' membership and functions (Berkowitz \& Bor, 2017; Lawton et al., 2017; Spillman, 2017). Some meta-organizations are CSR business only, while others gather multiple stakeholder. Their dissimilarities may differently impact their role in governance of innovation. Studying these different forms of invites to focus on their role in the diffusion of sustainable innovations, whether they are self-regulatory innovations, technical innovations, managerial innovations, etc. Such boundary organizations, i.e. organizations that allow collaborations among actors with unaligned interests (O’Mahony \& Bechky, 2008), raise 
questions of tensions and conflicts that can affect the development and diffusion of sustainable innovation. This also invites to further study how varying forms of meta-organizations may differently foster the development of specific organizational capabilities. Qualitative Comparative Analyses (QCA) methodologies may be helpful in investigating this matter.

Further, some meta-organizations are sectoral, as it is the case of IPIECA or IOGP, in the oil and gas industry, that we studied in this paper. However, other meta-organizations exist at all levels and put into question the relevance of the sectoral category to study governance of sustainable innovation at the meta-level. The Global Business Initiative for Human Rights (GBI) is a cross-sectoral meta-organization that builds collective responses to human rights issues (Berkowitz et al., 2017). Organizations often multiply membership in many different metaorganizations to increase knowledge transfers (Berkowitz \& Bor, 2017). This raises the question of optimal membership in cross-sectoral meta-organizations to build resilience and reflexivity and the necessity to multiply membership in various meta-organizations, through institutional complementarity (Aoki, 2001). Identifying the optimal frontier for meta-organization membership would help frame robust action strategies for businesses (Etzion et al., 2015).

Global Value Chain and supply chain governance. Bush, Oosterveer, Bailey, and Mol (2015) conduct a review of the sustainability governance in supply and value chains and networks literature. They argue that there is an overall weak conceptualization of governance mechanisms and devices. The concept of meta-organization may be useful to analyze supply chain metagovernance and broader inter-organizational relations governance, as Berkowitz and Bor (2017) recently suggested. Especially, the attributes of meta-organizations we have uncovered may help understand the development of innovations that are sustainable for the whole value chain, in a system approach. Exploring the meta-governance of value chains may allow to tackle negative externalities, for instance those affecting the ocean (marine sound, plastic pollution, overfishing) and that have been neglected, through a more comprehensive approach of sustainable innovation.

Unconventional meta-organizations such as eco-patent pools or sustainable development oriented crowdfunding platforms. Meta-governance of sustainable innovation covers a broad range of phenomena that can be studied through our framework of capabilities and attributes. For 
example, patent pools constitute another form of meta-organization that can foster innovation. Eco-patent pools, i.e. pools of eco-friendly patents, such as Eco-patent Commons, are confronted to organizational and coopetitive challenges that need to be further investigated. In a different sector, crowdfunding platforms that target renewable energy projects can also be analyzed as meta-organizations. It raises several questions related to our framework, e.g. in what sense the information available on these crowdfunding platforms may allow users to anticipate projects or companies' risks and what kind of mechanisms foster resilience.

Ultimately, reflecting in terms of meta-organizing capabilities for sustainable innovation allows to build a more reflexive, inclusive and participatory framework for the meta-governance of organizations. This approach requires to investigate philosophical, moral and ethical foundations of collective action at the level of organization (or meta-organizing). It also requires to further analyze the contribution of different meta-organization's families to organizational capabilities for sustainable innovation. The end-goal would consist in developing a more normative approach of sustainable innovation and meta-organizations, in line with Berkowitz and Bor (2017) recent call, thus identifying levers of action for the diffusion of sustainable innovations.

\section{CONCLUSION}

Our paper contributes to the literature on sustainable innovation first by providing a more comprehensive approach of organizational capabilities for sustainable innovation. Second, it contributes to the debate on governance, by showing the roles meta-organizations may play in the collective building of such capabilities in firms and entrepreneurs. This leads us to suggest a research agenda based on families of meta-organizations, from global value chain governance to entrepreneurial meta-organizations (such as fablabs), to further investigate the meta-governance of sustainable innovation as a credible alternative to regulation or markets alone. Beyond, such research program would benefit from developing a philosophical reflection on today's governance turn. Especially, it would be useful to reflect on the necessity to 'meta-organize' organizations' actions to tackle grand challenges. 


\section{REFERENCES}

Adapa, S., Bhullar, N., \& de Souza, S. V. (2016). A systematic review and agenda for using alternative water sources for consumer markets in Australia. Journal of Cleaner Production, 124, 14-20. https://doi.org/10.1016/j.jclepro.2016.02.083

Ahrne, G., \& Brunsson, N. (2005). Organizations and meta-organizations. Scandinavian Journal of Management, 21(4), 429-449.

Ahrne, G., \& Brunsson, N. (2008). Meta-organizations. Cheltenham, Glos, UK; Northampton, MA, USA: Edward Elgar Publishing.

Ahrne, G., \& Brunsson, N. (2010). Organization outside organizations: the significance of partial organization. Organization, 18(1), 83-104.

Ahrne, G., Brunsson, N., \& Seidl, D. (2016). Resurrecting organization by going beyond organizations. European Management Journal, 34(2), 93-101.

Aoki, M. (2001). Toward a comparative institutional analysis. Cambridge, MA: MIT press.

Bagatin, R., Klemeš, J. J., Reverberi, A. P., \& Huisingh, D. (2014). Conservation and improvements in water resource management: a global challenge. Journal of Cleaner Production, 77, 1-9.

Beermann, M. (2011). Linking corporate climate adaptation strategies with resilience thinking. Journal of Cleaner Production, 19(8), 836-842.

Berkowitz, H., \& Bor, S. (2017). Why Meta-Organizations Matter: A Response to Lawton et al. and Spillman. Journal of Management Inquiry, OnlineFirst. Retrieved from http://journals.sagepub.com/eprint/XYqEiCKF4JAWgVRPGeAS/full

Berkowitz, H., Bucheli, M., \& Dumez, H. (2017). Collective CSR strategy and the role of metaorganizations: a case study of the oil and gas industry. Journal of Business Ethics, 143(4), 753-769.

Berkowitz, H., \& Dumez, H. (2016). The Concept of Meta-Organization: Issues for Management Studies. European Management Review, 13(2), 149-156.

Blok, V., \& Lemmens, P. (2015). The Emerging Concept of Responsible Innovation. Three Reasons Why It Is Questionable and Calls for a Radical Transformation of the Concept of Innovation. In B.-J. Koops, I. Oosterlaken, H. Romijn, T. Swierstra, \& J. van den Hoven (Eds.), Responsible innovation 2: concepts, approaches, and applications (pp. 19-36). Cham: Springer.

Bohas, A., Camus, A., Capdevilla, I., Dandoy, A., Fabbri, J., Glaser, A., ... others. (2016). Coworkers, Makers and Hackers in the city: Reinventing policies, corporate strategies and citizenship? Research Group on Collaborative Spaces. Retrieved from https://halshs.archives-ouvertes.fr/halshs-01426513/

Boons, F., Montalvo, C., Quist, J., \& Wagner, M. (2013). Sustainable innovation, business models and economic performance: an overview. Journal of Cleaner Production, 45, 18.

Bor, S. (2014). A theory of meta-organisation: An analysis of steering processes in European Commission-funded R\&D "Network of Excellence" consortia (Ph.D. thesis). Helsinki: Hanken School of Economics. Retrieved from http://hdl.handle.net/10138/144154.

Boström, M. (2006). Regulatory credibility and authority through inclusiveness: Standardization organizations in cases of eco-labelling. Organization, 13(3), 345-367.

Boström, M., Jönsson, A. M., Lockie, S., Mol, A. P. J., \& Oosterveer, P. (2015). Sustainable and responsible supply chain governance: challenges and opportunities. Journal of Cleaner Production, 107, 1-7.

Braczyk, H.-J., Cooke, P. N., \& Heidenreich, M. (1998). Regional Innovation Systems: The Role of Governances in a Globalized World. Psychology Press.

Brandenburger, A., \& Nalebuff, B. (1996). Co-opetition. New York: Harper Collins Business.

Brès, L., Raufflet, E., \& Boghossian, J. (2017). Pluralism in Organizations: Learning from Unconventional Forms of Organizations. International Journal of Management Reviews, n/a-n/a. 
Brusco, S. (1990). The idea of the industrial districts: Its genesis. In F. Pyke, G. Becattini, \& W. Sengenberger (Eds.), Industrial Districts and Inter-firm co-operation in Italy. (pp. 1019). Geneva: International Institute for Labour Studies.

Bush, S. R., Oosterveer, P., Bailey, M., \& Mol, A. P. J. (2015). Sustainability governance of chains and networks: a review and future outlook. Journal of Cleaner Production, 107, $8-19$.

Callon, M., Lascoumes, P., \& Barthe, Y. (2009). Acting in an Uncertain World: An Essay on Technical Democracy. Cambridge, MA: MIT Press.

Capdevila, I. (2015). Co-working spaces and the localised dynamics of innovation in Barcelona. International Journal of Innovation Management, 19(3), 1540004.

Capdevila, I., \& Zarlenga, M. I. (2015). Smart city or smart citizens? The Barcelona case. Journal of Strategy and Management, 8(3), 266-282.

Carrillo-Hermosilla, J., del Río, P., \& Könnölä, T. (2010). Diversity of eco-innovations: Reflections from selected case studies. Journal of Cleaner Production, 18(10-11), 1073-1083.

Chaudhry, R., Fischlein, M., Larson, J., Hall, D. M., Peterson, T. R., Wilson, E. J., \& Stephens, J. C. (2013). Policy stakeholders' perceptions of carbon capture and storage: a comparison of four US States. Journal of Cleaner Production, 52, 21-32.

Chaudhury, A. S., Ventresca, M. J., Thornton, T. F., Helfgott, A., Sova, C., Baral, P., ... Ligthart, J. (2016). Emerging meta-organisations and adaptation to global climate change: Evidence from implementing adaptation in Nepal, Pakistan and Ghana. Global Environmental Change, 38, 243-257.

Child, J. (2005). Organization: contemporary principles and practice. Malden: Blackwell.

Christ, K. L., \& Burritt, R. L. (2015). Material flow cost accounting: a review and agenda for future research. Journal of Cleaner Production, 108, 1378-1389.

Ciborra, C. U. (1996). The platform organization: Recombining strategies, structures, and surprises. Organization Science, 7(2), 103-118.

Clarysse, B., Wright, M., Bruneel, J., \& Mahajan, A. (2014). Creating value in ecosystems: Crossing the chasm between knowledge and business ecosystems. Research Policy, 43(7), 1164-1176.

Coase, R. H. (1937). The nature of the firm. Economica, 4(16), 386-405.

Cohendet, P., Grandadam, D., Simon, L., \& Capdevila, I. (2014). Epistemic communities, localization and the dynamics of knowledge creation. Journal of Economic Geography, 14(5), 929-954.

Corral, C. M. (2003). Sustainable production and consumption systems-cooperation for change: assessing and simulating the willingness of the firm to adopt/develop cleaner technologies. The case of the In-Bond industry in northern Mexico. Journal of Cleaner Production, 11(4), 411-426.

Davis, S. R., \& Horst, M. (2015). Responsible innovation in the US, UK and Denmark: Governance Landscapes. In B.-J. Koops, I. Oosterlaken, H. Romijn, T. Swierstra, \& J. van den Hoven (Eds.), Responsible innovation 2: concepts, approaches, and applications (pp. 37-56). Cham: Springer.

De Saille, S. (2015). Innovating innovation policy: The emergence of "responsible research and innovation." Journal of Responsible Innovation, 2(2), 152-168.

Etzion, D., Gehman, J., Ferraro, F., \& Avidan, M. (2015). Unleashing sustainability transformations through robust action. Journal of Cleaner Production, Online.

Fabbri, J., \& Charue-Duboc, F. (2013). The Role of Physical Space in Collaborative Workplaces Hosting Entrepreneurs: The Case of the "Beehive"in Paris. In Materiality and Space (pp. 117-134). Palgrave Macmillan UK.

Fleming, L., King, C., \& Juda, A. I. (2007). Small Worlds and Regional Innovation. Organization Science, 18(6), 938-954. https://doi.org/10.1287/orsc.1070.0289

Francesch-Huidobro, M. (2015). Collaborative governance and environmental authority for adaptive flood risk: recreating sustainable coastal cities: Theme 3: pathways towards urban modes that support regenerative sustainability. Journal of Cleaner Production, 107, 568-580. 
Freeman, R. E., Wicks, A. C., \& Parmar, B. (2004). Stakeholder Theory and "The Corporate Objective Revisited." Organization Science, 15(3), 364-369.

Fung, A., \& Wright, E. O. (2003). Deepening democracy: Institutional innovations in empowered participatory governance (Vol. 4). Verso.

Gawer, A. (2014). Bridging differing perspectives on technological platforms: Toward an integrative framework. Research Policy, 43(7), 1239-1249.

Gawer, A., \& Cusumano, M. A. (2014). Industry platforms and ecosystem innovation. Journal of Product Innovation Management, 31(3), 417-433.

Gaziulusoy, A. İ., Boyle, C., \& McDowall, R. (2013). System innovation for sustainability: a systemic double-flow scenario method for companies. Journal of Cleaner Production, 45, 104-116.

Grutter, J. M., \& Egler, H.-P. (2004). From cleaner production to sustainable industrial production modes. Journal of Cleaner Production, 12(3), 249-256.

Gulati, R., Puranam, P., \& Tushman, M. (2012). Meta-organization design: Rethinking design in interorganizational and community contexts. Strategic Management Journal, 33(6), $571-586$.

Hankins, J. (2013). Endnotes: Building Capacity for Responsible Innovation. In R. Owen, J. Bessant, \& M. Heintz (Eds.), Responsible Innovation (pp. 269-273). Chichester: John Wiley \& Sons.

Hillman, K., Nilsson, M., Rickne, A., \& Magnusson, T. (2011). Fostering sustainable technologies: a framework for analysing the governance of innovation systems. Science \& Public Policy (SPP), 38(5), 403-415.

Iles, A. (2007). Making the seafood industry more sustainable: creating production chain transparency and accountability. Journal of Cleaner Production, 15(6), 577-589.

IPIECA-IOGP Oil Spill Response Joint Industry Project. (2014). Guidelines for the selection of in-situ burning equipment (Oil Spill Response Joint Industry Project).

Jänicke, M. (2008). Ecological modernisation: new perspectives. Journal of Cleaner Production, 16(5), 557-565.

Jiao, W., \& Boons, F. (2014). Toward a research agenda for policy intervention and facilitation to enhance industrial symbiosis based on a comprehensive literature review. Journal of Cleaner Production, 67, 14-25.

Koops, B.-J. (2015). The Concepts Approaches, and Applications of Responsible Innovation. In B.-J. Koops, I. Oosterlaken, H. Romijn, T. Swierstra, \& J. van den Hoven (Eds.), Responsible innovation 2: concepts, approaches, and applications (pp. 1-18). Cham: Springer.

Koops, B.-J., Oosterlaken, I., Romijn, H., Swierstra, T., \& van den Hoven, J. (2015). Responsible innovation 2: concepts, approaches, and applications. Cham: Springer.

Lawton, T. C., Rajwani, T., \& Minto, A. (2017). Why trade associations matter: Exploring function, meaning, and influence. Journal of Management Inquiry, 1056492616688853.

Lee, R. G., \& Petts, J. (2013). Adaptive Governance for Responsible Innovation. In R. Owen, J. Bessant, \& M. Heintz (Eds.), Responsible Innovation: Managing the Responsible Emergence of Science and Innovation in Society (pp. 143-164). Chichester: John Wiley $\&$ Sons.

Leys, V., \& Joffre, P. (2014). Méta-organisations et évolution des pratiques managériales. Revue française de gestion, (241), 121-134.

Malcourant, E., Vas, A., \& Zintz, T. (2015). World Anti-Doping Agency: a meta-organizational perspective. Sport, Business and Management: An International Journal, 5(5), 451471.

March, J. G. (2007). The Study of Organizations and Organizing Since 1945. Organization Studies, 28(1), 9-19.

March, J. G., Schulz, M., \& Zhou, X. (2000). The dynamics of rules. Stanford; CA: Stanford University Press.

March, J. G., \& Simon, H. A. (1958). Organizations. New York: Wiley. 
Marine Mammal Commission. (2007). Marine Mammals and Noise: A Sound Approach to Research And Management. A Report to Congress from the Marine Mammal Commission.

Matos, S., \& Silvestre, B. S. (2013). Managing stakeholder relations when developing sustainable business models: the case of the Brazilian energy sector. Journal of Cleaner Production, 45, 61-73.

Meyer, M. H., \& Lehnerd, A. P. (2002). The power of product platforms: building value and cost leadership. 1997 (Vol. 10020). New York: Free Press.

Miles, M. B., \& Huberman, A. M. (1994). Qualitative data analysis: An expanded sourcebook. Sage.

Nielsen, K. R., Reisch, L. A., \& Thøgersen, J. (2016). Sustainable user innovation from a policy perspective: a systematic literature review. Journal of Cleaner Production, 133, 65-77.

O’Mahony, S., \& Bechky, B. A. (2008). Boundary organizations: Enabling collaboration among unexpected allies. Administrative Science Quarterly, 53(3), 422-459.

Owen, R., Bessant, J., \& Heintz, M. (Eds.). (2013). Responsible Innovation: Managing the Responsible Emergence of Science and Innovation in Society. John Wiley \& Sons, Ltd.

Owen, R., Stilgoe, J., Macnaghten, P., Gorman, M., Fisher, E., \& Guston, D. (2013). A Framework for Responsible Innovation. In R. Owen, J. Bessant, \& M. Heintz (Eds.), Responsible Innovation: Managing the Responsible Emergence of Science and Innovation in Society (pp. 27-50). Chichester: John Wiley \& Sons.

Patrus, R., Neto, A., Coelho, H., \& Teodosio, A. (2013). Corporate Social Responsibility and Labor Relations: A Research Agenda about Internal Stakeholders Management in UN's Global Compact Signatory Corporations. Revista Brasileira de Gestão de Negocios, 15(46), 22-38.

Porter, M. E. (1990). The competitive advantage of nations. New York: Free Press.

Pyke, F., \& Sengenberger, W. (1990). Introduction. In F. Pyke, G. Becattini, \& W. Sengenberger (Eds.), Industrial Districts and Inter-firm co-operation in Italy. (pp. 1-9). Geneva: International Institute for Labour Studies.

Rajwani, T., Lawton, T. C., \& Phillips, N. (2015). The "Voice of Industry": Why management researchers should pay more attention to trade associations. Strategic Organization, 13(3), 224-232.

Rasche, A., Bakker, F., \& Moon, J. (2013). Complete and Partial Organizing for Corporate Social Responsibility. Journal of Business Ethics, 115(4), 651-663.

Saxenian, A. (1996). Regional advantage: Culture and Competition in Silicon Valley and Route 128. Cambridge, MA: Harvard University Press.

Saxenian, A. (2006). The new argonauts. Cambridge, MA: Harvard University Press.

Spence, J., Fischer, R., Bahtiarian, M., Boroditsky, L., Jones, N., \& Dempsey, R. (2007). Review of existing and future potential treatments for reducing underwater sound from $O \& G$ industry activities. Joint Industry Programme on E\&P Sound and Marine Life.

Spillman, L. (2017). Meta-Organization Matters. Journal of Management Inquiry, Online Preview.

Stahl, B. C., Eden, G., \& Jirotka, M. (2013). Responsible Research and Innovation in Information and Communication Technology: Identifying and Engaging with the Ethical Implications of ICTs. In R. Owen, J. Bessant, \& M. Heintz (Eds.), Responsible Innovation: Managing the Responsible Emergence of Science and Innovation in Society (pp. 199-218). Chichester: John Wiley \& Sons.

Stark, D. (2009). The Sense of Dissonance. Accounts of Worth in Economic Life. Princeton: Princeton University Press.

Stephens, J. C., \& Graham, A. C. (2010). Toward an empirical research agenda for sustainability in higher education: exploring the transition management framework. Journal of Cleaner Production, 18(7), 611-618.

Stilgoe, J., Owen, R., \& Macnaghten, P. (2013). Developing a framework for responsible innovation. Research Policy, 42(9), 1568-1580.

Sykes, K., \& Macnaghten, P. (2013). Responsible Innovation - Opening Up Dialogue and Debate. In R. Owen, J. Bessant, \& M. Heintz (Eds.), Responsible Innovation: Managing 
the Responsible Emergence of Science and Innovation in Society (pp. 85-107). Chichester: John Wiley \& Sons.

Torraco, R. J. (2005). Writing integrative literature reviews: Guidelines and examples. Human Resource Development Review, 4(3), 356-367.

van Kleef, J. A. G., \& Roome, N. J. (2007). Developing capabilities and competence for sustainable business management as innovation: a research agenda. Journal of Cleaner Production, 15(1), 38-51.

Voegtlin, C., \& Scherer, A. G. (2015). Responsible innovation and the innovation of responsibility: Governing sustainable development in a globalized world. Journal of Business Ethics, 1-17.

Von Schomberg, R. (2011). Towards responsible research and innovation in the information and communication technologies and security technologies fields.

Weber, M. (1921). Wirtschaft und Gesellschaft. Germany: Mohr: Tübingen.

Wennersten, R., Sun, Q., \& Li, H. (2015). The future potential for Carbon Capture and Storage in climate change mitigation-an overview from perspectives of technology, economy and risk. Journal of Cleaner Production, 103, 724-736.

Zollo, M., Cennamo, C., \& Neumann, K. (2013). Beyond what and why: Understanding organizational evolution towards sustainable enterprise models. Organization \& Environment, 26(3), 241-259. 